\title{
EXTRACTION OF HOUSES FROM POINT CLOUD LIDAR: PROBLEMS AND CHALLENGE
}

\author{
Guoqing Zhou ${ }^{1, *}$, Weiqi $\mathrm{Di}^{2}$ \\ ${ }^{1}$ Guangxi Key Laboratory of Spatial Information and Geomatics, Guilin University of Technology, \\ 12 Jian'gan Road, Guilin, Guangxi 541004, China \\ ${ }^{2}$ College of Earth Sciences
}

Tel: +86 (773)-5896073; Fax: +86 (773)5892796; E-mail: gzhou@glut.edu.cn

KEY WORDS: Image Processing, Aerial Image, LiDAR, Extraction, House, Urban

\begin{abstract}
:
Although many efforts have been made on the extraction of houses from LiDAR (Light Detection and Ranging) and/or aerial imagery and/or their fusion, little investigation using co-registration between the orthoimage map and LiDAR on the basis of geodetic coordinates as element for house extraction. For this reason, this paper first overviews the advances of LiDAR and investigates the advantages and disadvantages of LiDAR system vs. traditional photogrammetry, and then indicates that LiDAR technology has not yet resolved all existing problems that traditional photogrammetry remained so far, such as texture information, LiDAR point cloud density. A comprehensive comparison in extraction of houses (feature information) from LiDAR data set and from aerial imagery are also presented. It has been widely accepted and admitted that full automation for extraction of houses (feature information in city area) from LiDAR point cloud has still been difficult. Therefore, this paper proposes a human-computer interaction operation for houses extraction through combination of LiDAR point cloud and the orthorectified high-resolution aerial imagery. The real data is utilized for validation of the proposed method.
\end{abstract}

\section{INTRODUCTION}

Extraction of houses from airborne-based aerial imagery, or spaceborne-based high-resolution satellite imagery to create digital building model (DBM) have investigated for more than 100 years. I recalled that when I was in the fresh year of the undergraduate student in 1980 s, the lectures in university told us that the AUTOMATIC extraction of houses/buildings from high-resolution aerial images have been a very hot topic of research worldwide. This is because an increasing need for continuously updating urban three-dimensional (3D) DBM in rapidly change city area, especially in the most current digital/smart city construction in China and the a variety of applications such as microclimate investigation of city streets, transmitter placement in telecommunication in high-density city area, noise simulation for industrial city area using 3D DBM, heat and exhaust spreading with different materials in big cities, traffic monitoring using GPS-based car track real data, and security surveillances at night, etc. However, traditional photogrammetry method has encountered many challenges for generations of DBM, digital surface model (DSM), or digital terrain model (DTM) in those complicated city scenes, such as dense buildings, very-high buildings. The degradation in the performance of photogrammetric automatic processes is mainly due to the failures of image matching, which are primarily caused by, for example, occlusions, depth discontinuities, shadows, poor or repeated textures, poor image quality, foreshortening and motion artifacts, and the lack of model of man-made objects. Therefore, a human-guided interactive operations, such as stereo compilation on screen in traditional photogrammetry are still be applicable.

However, the emerging LiDAR (Light Detection And Ranging) in the end of 1980s and the beginning of 1990s had been considered as the revolution of photogrammetric stereo matching, since the LiDAR directly obtains the 3D point cloud data without conducting a stereo matching. The LiDAR technology become thereby very doable for 3D DBM generation in city area with highly dense buildings. Consequently, a variety of different methods and algorithms in photogrammetric community have been proposed for extraction of houses over last decades of years. For example, early investigations in 1990s include, but are not limited to, Axelsson (1999), Baltsavias et al. (1999), Hug (1997), Haala et al. (1998), Lindenberger (1993) and Wehr and Lohr (1999); and in the beginning of 2000s, such as Morgan and Tempfli (2000); Morgan and Habib(2002), Vosselman (2000), Wang et al. (2009), Axelsson (2000), Sithole and Vosselman (2004), Yoon et al. (2002). These methods and algorithms can be categorized into two groups (Zhou et al. 2004): the classification approach and the adjustment approach. The classification approach is used to detect the ground points using various operators, typically, mathematical morphology (e.g., Morgan and Tempfli 2000), terrain slope (Axelsson 1999), or local elevation difference. The adjustment approach essentially uses a mathematical function to approximate the ground surface. This method is determined with an iterative least-squares process, with which the outliers of non-ground points are eliminated, typically including $\mathrm{Pu}$ and Vosselman (2009), Rutzinger et al. (2009), Zhang et al. (2006), and Sampath and Shan (2007). The discussions can be referenced to Zhou et al. $(2014 ; 2004)$

In addition, the combination of LiDAR data and high-resolution aerial images has also been studied for extraction of houses in the past decades of years duo to their complementary properties of each data source. For instance, Zhou et al. (2004; 2014),

\footnotetext{
* Corresponding author: Guoqing Zhou; E-mail: gzhou@glut.edu.cn
} 
Hermosilla et al. (2011), Kabolizade et al. (2010), Hu et al. (2007), Gamba et al. (2002) and Yu et al. (2009) presented the method for extraction of urban houses and road networks through the integration of LiDAR and aerial images. Schenk and Csatho (2002) and Habib et al. (2005) proposed featurebased data fusion of LiDAR point cloud data and highresolution aerial imagery. Sohn and Dowman (2007) focused on the exploitation of IKONOS multi-spectral imagery in combination with LiDAR DEM for house extraction. Rottensteiner et al. (2007) proposed a method to detect building roof and determine the roof boundaries. Fujii and Arikawa (2002) proposed integrating LiDAR, aerial image and ground images for modeling the urban building. O'Donohue et al. (2008) combined thermal-LiDAR imagery for the extraction of urban man-made objects. Zabuawala et al. (2009), Wang and Neumann (2009), Mastin et al. (2009), Dong et al. (2008) suggested automatic registration of LiDAR and optical imagery for the extraction of urban houses and roads.

Since the original aerial images have no geodetic coordinates, contain various types of geometric distortions. As a result, the LiDAR point cloud data is difficult to co-register with aerial image. Thus, this paper proposes the original aerial images are first orthorectified to a given geodetic coordinate system and then co-register with LiDAR point cloud data. After that, the extraction of houses is conducted from the combined data set.

\section{LIDAR AND PHOTOGRAMMETRIC TECHNOLOGIES}

\subsection{Traditional Photogrammetric Technologic Challenges}

As mentioned above, traditional photogrammetry is an important tool for generation of digital building model (DBM), digital surface model (DSM), or digital terrain model (DTM). Moreover, the performance of these systems is very good, efficient and cost effective in smooth terrain with small and medium scale imagery (Baillard, 1999; Simonetto et al., 2005). However, it decreases rapidly in complicated urban areas with dense buildings. This is because traditional photogrammetric method using stereo matching, which exposes the challenging as follows (see Figure 1).

- Occlusions

- Depth discontinuities

- Shadows

- Poor or repeated textures

- Poor image quality

- Foreshortening and motion artifacts

- Lack of model of man-made objects

These challenges above cannot be resolved using the traditional stereo match if no human-computer interaction is conducted. Thus new, novel, even revolution technologies have to be hunted for.

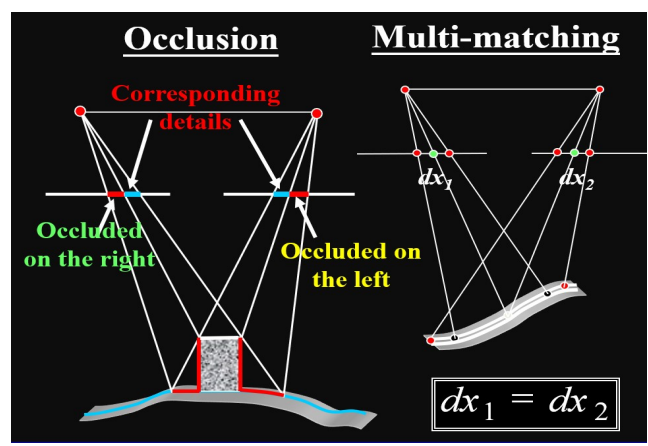

Figure 1: The degradation in the performance of photogrammetric matching in the complicated scene in city area

\subsection{LiDAR Technologic Challenges}

LiDAR technology emerged in the end of 1980s was majorly applied for 3D point cloud data collection. From a viewpoint of photogrammetry, the LiDAR system did resolve a few inherit problems that photogrammetry have encountered, but cannot effectively resolved for decades of years. The two typical terrestrial scanning LiDAR systems are " $Z$ " and "Cone" scanning styles (see Figure 2).
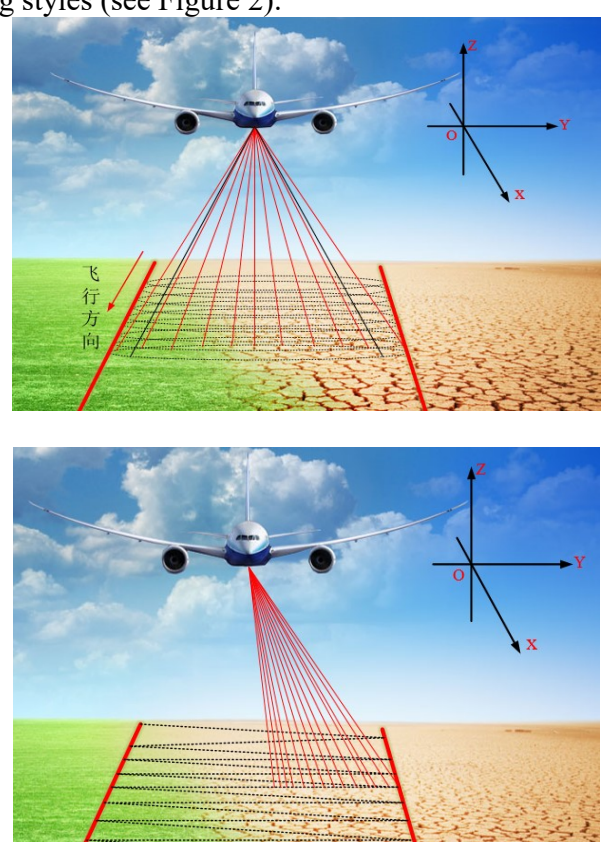

Figure 2: Two basic types of LiDAR scanning systems for point cloud data collection

The traditional scanning LiDAR systems are not suitable for rapid 3D terrain generation at a real-time manner, i.e., DTM generation, duo to its clumsy heavy weight, big volume, and delay for post-processing for 3D point cloud data (Zhou et al. $2015 ; 2014)$. For this reason, 3D flash laser sensor (also called "array LiDAR system") has been developed in recent years. The array LiDAR sensor is analogous to a camera with a flashbulb (flood illumination) (see Fig. 3), but with the flash being provided by laser illumination and the use of an array detector, such as array APD detector with a clock to determine the time it takes from emitting to retrieving. The flash Lidar systems are being widely applied in different fields such as terrain mapping, autonomous safe landing, Drogue tracking, obstacle avoidance, range navigation, ocean wave reconstruction, and environmental monitoring, etc. (Zhou et al. 2015). 


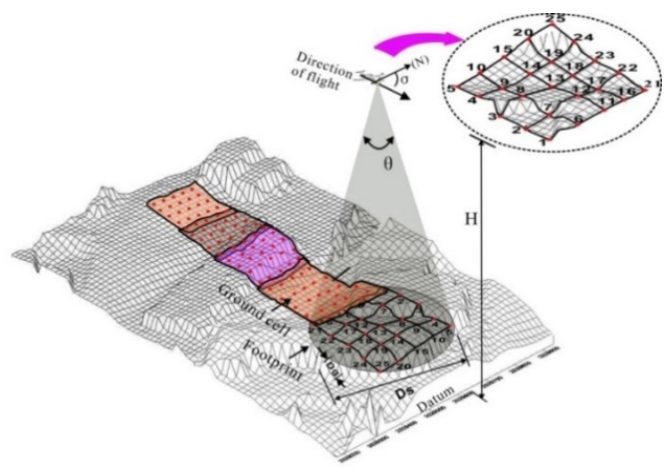

Figure 3: a $5 \times 5$ array (flash) LiDAR system for point cloud data collection (Courtesy of Zhou et al. (2015))

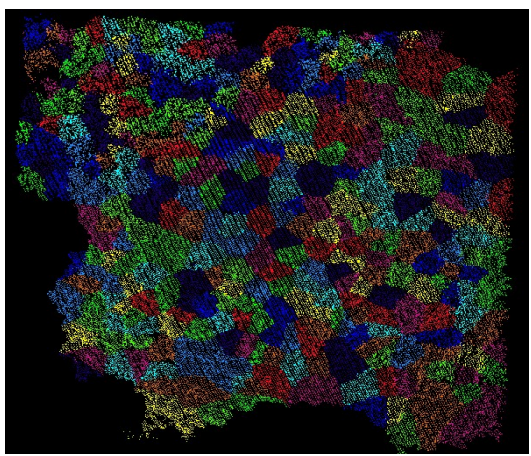

Figure 4: LiDAR point cloud data

2.3 Comparison Analysis between LiDAR point cloud and aerial image

Although LiDAR system has really successfully resolved a few inherit problems that photogrammetry have encountered, but cannot effectively provide rich texture information, i.e., the new problem has emerged with LiDAR data. Firstly, the LiDAR point cloud cannot reach the same density as the aerial photogrammetry does (e.g., $25 \mathrm{~cm}$ ground sample distance, GSD) (see Figure 4); secondly, the LiDAR cannot provide as rich texture information as the aerial photogrammetry does (see Figure 5); and last, the LiDAR system sometime received multiechoes in forest area (e.g., trees), result in that it is hard to conduct post-processing at a near real-time mode (Baltsavias, 1999).

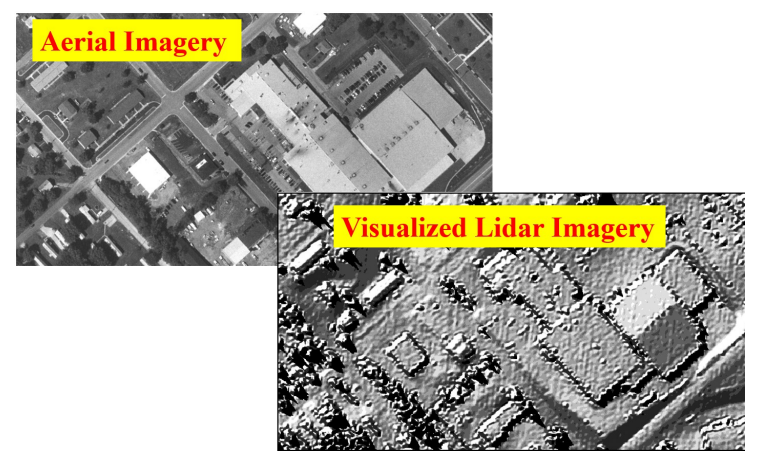

Figure 5: Texture information comparison between aerial imagery vs. LiDAR data set (Courtesy of Zhou et al. (2004))

In addition to the differences of the two data sets themselves, the post-processing is still different. For example, the operations for DSM, DTM and DBM generations from both aerial imagery and LiDAR point cloud need human-computer interaction, this means that it is rather difficult to implement a full automation for production of DBM (see Table 1). Also, the extraction of feature information from both aerial imagery and LiDAR point cloud need human-computer interaction, that means that it is rather difficult to implement a full automation for extraction of feature information in city area (see Table 2).

Table 1: Comparison analysis for DSM, DTM and DBM generation from aerial imagery vs. LiDAR data set

\begin{tabular}{|c|c|c|c|c|}
\hline & \multicolumn{2}{|c|}{ Aerial imagery } & \multicolumn{2}{|c|}{ LiDAR point cloud } \\
\hline & $\begin{array}{l}\text { Human- } \\
\text { computer } \\
\text { interaction }\end{array}$ & $\begin{array}{c}\text { Full } \\
\text { automation }\end{array}$ & $\begin{array}{l}\text { Human- } \\
\text { computer } \\
\text { interaction }\end{array}$ & $\begin{array}{c}\text { Full } \\
\text { automation }\end{array}$ \\
\hline DSM & YES & Yes/No, & YES & Yes/No, \\
\hline DTM & YES & upon the & YES & upon the \\
\hline DBM & YES & $\begin{array}{c}\text { smooth } \\
\text { terrain, or } \\
\text { complicated } \\
\text { city area }\end{array}$ & YES & $\begin{array}{l}\text { smooth } \\
\text { terrain, or } \\
\text { complicated } \\
\text { city area }\end{array}$ \\
\hline
\end{tabular}

Table 2: Comparison analysis for feature information extraction from aerial imagery vs. LiDAR data set

\begin{tabular}{|c|c|c|c|c|}
\hline & \multicolumn{2}{|c|}{ Aerial imagery } & \multicolumn{2}{c|}{ LiDAR point cloud } \\
\hline & $\begin{array}{c}\text { Human- } \\
\text { computer } \\
\text { interaction }\end{array}$ & $\begin{array}{c}\text { Full } \\
\text { automatio } \\
\mathrm{n}\end{array}$ & $\begin{array}{c}\text { Human- } \\
\text { computer } \\
\text { interaction }\end{array}$ & $\begin{array}{c}\text { Full } \\
\text { automatio } \\
\mathrm{n}\end{array}$ \\
\hline $\begin{array}{c}\text { Extractio } \\
\text { n of } \\
\text { feature }\end{array}$ & YES & $\begin{array}{c}\text { Yes/No, } \\
\text { upon the }\end{array}$ & YES & $\begin{array}{c}\text { Yes/No, } \\
\text { upon the } \\
\text { informati } \\
\text { on (road, } \\
\text { car, etc.) }\end{array}$ \\
& & $\begin{array}{c}\text { smooth } \\
\text { terrain, or } \\
\text { complicat } \\
\text { ed city } \\
\text { area }\end{array}$ & & $\begin{array}{c}\text { terrain, or } \\
\text { complicat } \\
\text { ed city } \\
\text { area }\end{array}$ \\
\hline
\end{tabular}

\section{METHOD FOR HOUSE EXTRACTION FROM TRUE ORTHOIMAGE AND LIDAR POINT CLOUD}

\subsection{True Orthoimage Generation}

In order to orthorectify the relief displacement caused by high of the buildings onto its correct, upright, true positions using differential orthorectification method, the buildings must be modelled using 3D. In addition, the relief displacement caused by terrain also must be orthorectified, which implies terrestrial surface must be represented using digital terrain mode (DTM), which does not contain buildings and vegetation. Therefore, the basic steps of orthoimagery generation in city area include both DTM-based orthoimagery generation and DSM-based orthoimagery generation, their merging, as well as other works, such as occlusions detection and compensation, and shadow detection and removal (Zhou et al. 2004; 2007; 2014).

\subsubsection{Data Input}

The data to be inputted include: (1) the unrectified raster raw imagery, (2) sensor's interior orientation elements (IOEs) (focal length, principal point coordinates, lens distortion parameters), and the sensor's exterior orientation elements (EOEs) (three position elements and three angle elements), (3) well-distributed ground control points (GCPs), (4) digital terrain model (DTM), (5) digital building model (DBM), and (6) other parameters such as datum, reference coordinate system, earth curvature, etc. The details can be referenced to Zhou et al. (2005). 


\subsubsection{True Orthoimagery Generation}

- DBM-Based orthoimagery generation: The generation of DBM-based orthoimagery uses DBM data to orthorectify only the displacement caused by buildings. The detailed method can be referenced to Zhou et al. $(2004 ; 2005)$. Because of the existence of building occlusion in city area, this means that areas occluded by objects need to be filled by using other orthoimagery, thereby, this the orthorectified imagery is called slave orthoimagery.

- DTM-based orthoimagery generation: The generation of DTM-based orthoimagery is for orthorectifying the relief displacement caused only by terrain without considering the displacement caused by buildings. The detailed method can be referenced to Zhou et all $(2004 ; 2005)$.

- Occlusion detection and compensation: In highly density urban area, the tall buildings usually occlude low buildings and terrain. To solve this problem, Zhou et al. (2004; 2005) suggested a method using cross-strip imagery and alongstrip imagery with over $75 \%$ overlap. The process of occlusion compensation requires finding conjugate areas in adjacent slave orthoimages and then filling the occluded area using orthoimagery patches. The detailed method can be referenced to Zhou et al. $(2004 ; 2005 ; 2017)$.

\subsection{Building Extraction}

\subsubsection{Co-registration between Orthoimagery and LiDAR Point Cloud}

The orthoimages are an orthorectified image in a given geodetic coordinate system, and the LiDAR point cloud is referenced to the WGS84 coordinate system. This means that datums of two data sets are different. For this reason, WGS84 is selected as the datum and the orthoimages are unified to the same datum. The linkage of the two data sets is implemented by the XY coordinates. The validation of co-registration is conducted by visual check. The details of this method can be referenced to Zhou et al. (2004).

\subsubsection{Extraction of Initial Edges of Houses from LiDAR Point Cloud}

This paper applies the segmentation method of the LiDAR point cloud. The detailed steps are:

Firstly, separating the ground and objects above earth surface using watershed algorithm: watershed algorithm belongs to one type of mathematical morphology algorithms, since this method is similar to the simulated water immersion process. This method visualizes the LiDAR point cloud data using gray values with a raster image format. The brightness of each pixel is corresponding to the height. The gray value is enhanced and filtered to enlarge the difference between the ground and object on the earth surface.

Secondly, distinguishing the trees and houses: a fourth-order polynomial equation fitting method is used for distinguish the trees and houses. First, using the dynamic size circular filter to detect the crown apex, and then fourth-order polynomial equation is applied to fit each of tree on the basis of tree shape structure.

Thirdly, extracting vegetation using the normalized difference (ND) of elevation. Two echoes, which are corresponding two elevations, are normalized to the range of $[-1,1]$. The ND values can be calculated by

$$
N D=\frac{D S M_{F}-D S M_{L}}{D S M_{F}+D S M_{L}}
$$

where $D S M_{F}$ is the elevation from first echo, and $D S M_{L}$ is the elevation from the last echo. DSM, standing for Digital Surface Model, means that the elevations at the first and last echoes, are from the DSM.

Fourthly, discriminating the houses and vegetation. Since both edge of the building and vegetations possibly have two echoes, resulting the height difference of the same object, the slope information and intensity information are combined to distinguish the vegetation and building edge information. The algorithms

$$
D T I=\left|D S M_{F}-D S M_{L}\right| \times t
$$

where

$$
t=\left\{\begin{array}{cc}
0, & \text { Slope } \geq T_{1} \text { and Intensity } \geq T_{2} \\
1, & \text { Others }
\end{array}\right.
$$

Slope represents the terrestrial slope located in the point of the DSM, and Intensity represents is the gray value, and $T_{1}$ and $T_{2}$ are the thresholds corresponding to the Slope and the Intensity .

\subsubsection{High-accuracy of House Extraction for DBM Creation}

With the initial edges of the houses, 4 corner coordinates of a house can be determined, noted as

$$
\begin{array}{llll}
\text { Corner 1: } & \left(X_{1}, Y_{1}\right) & \text { Corner 2: } & \left(X_{2}, Y_{2}\right) \\
\text { Corner 3: } & \left(X_{3}, Y_{3}\right) & \text { Corner 4: } & \left(X_{4}, Y_{4}\right)
\end{array}
$$

With 4 corner coordinates of a house, each edges of a house can be described using a straight line equation, i.e.,

$$
A X+B Y+C=0
$$

After the straight line equation is determined, whether are the LiDAR point cloud data located either inside or outside can be determined as well.

The above procedure is then repeated for each building until all houses are finished.

After extraction of each of roof, the LiDAR footprint within the building roof are obtained, associated with boundary information. Zhou et al. (2004) suggested an innovate method for extraction of high accuracy houses through fitting the building using planar equation in accordance with LiDAR footpoints within building roof's boundary. The planar equation is

$$
A X+B Y+C Z=1
$$

Where $A, B$ and $C$ are unknown parameters, $X, Y$ and $Z$ are coordinates of LiDAR data. As observed from Eq. (4), only three LiDAR points can determine the $A, B$ and $C$ are 
unknown parameters, which determines the surface of building. The details can be referenced to Zhou et al. (2004).

\section{EXPERIMENTS AND ANALYSES}

\subsection{Data Set}

The details of the experimental field can be referenced to Zhou et al. (2004; 2005). In summary, the Virginia Department of Transportation (VDOT), contracting to Woolpert L.L.C. at Richmond, Virginia, has established a high-accuracy test field in Wytheville, Virginia for the accuracy evaluation of the LiDAR system. The field is approximately 11.4 miles (WestEast) $\times 4.5$ miles (North-South) (Figure 6). The 19 GCP's accuracy averages $0.02 \mathrm{~m}, 0.02 \mathrm{~m}$, and $0.01 \mathrm{~m}$ in $\mathrm{X}, \mathrm{Y}$ and $\mathrm{Z}$, respectively. The density of spare LiDAR data is an average of 7.3 feet. LiDAR point cloud and 19 ground control points (GCPs) were referenced to NAD83/93 Virginia State Plane Coordinate system. The specification for the airborne LiDAR sensor is listed in Table 1 (Zhou et al. 2004).

Aerial images were collected using a Woolpert 5099 Camera at a focal length of $153.1 \mathrm{~mm}$ on September 19, 2000. The endlap and the sidelap of the images are about 65 percent and 30 percent, respectively. The specification for the camera is listed in Table 2 (Zhou et al. 2004). Imagery ID: 2523 is used for this experiment.

Table 1: Specification for LiDAR data collection

\begin{tabular}{|c|c|}
\hline $\begin{array}{l}\text { - System Name: Optech } \\
1210 \text { LiDAR system } \\
\text { - Date: September } 19 \text {, } \\
2000 \\
\text { - Accuracy: } 0.7 \mathrm{~m} \\
\text { - Density: about } 2.4 \mathrm{~m}\end{array}$ & $\begin{array}{l}\text { - Flight Speed: } 67 \mathrm{~m} / \mathrm{s} \\
\text { - Flying Height: } 1500 \mathrm{~m} \text { above ground } \\
\text { - Field of View: } \pm 16^{\circ} \\
\text { - Scan Frequency: } 14 \mathrm{~Hz} \\
\text { - Swath Width: } 860 \mathrm{~m} \\
\text { - Pulse Repetition Rate: } 10 \mathrm{KHz}\end{array}$ \\
\hline
\end{tabular}

Table 2: Specification for aerial image data collection

\begin{tabular}{l|ll} 
- Camera: Woolpert 5099 & - Scale: $1: 1000$ \\
- Film: Kodak 2405 & - Image type: B/W \\
- Focal length: $153.1 \mathrm{~mm}$ & - Pixel resolution: 2.0 pixels \\
- Total exposures: 96 & - Date: September 19, 2000
\end{tabular}

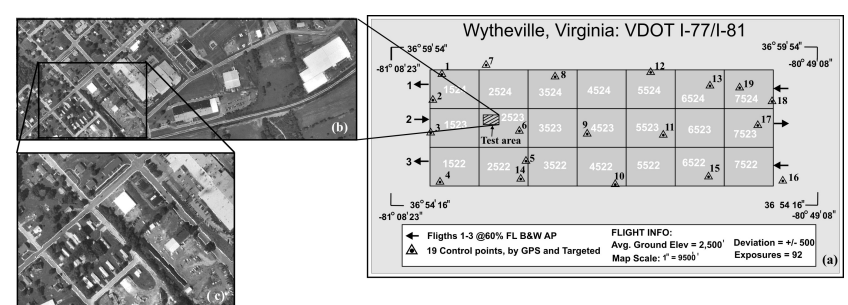

Figure 6: Geodetic control test field in Wytheville, VA (Courtesy of Zhou et al. (2004))

\subsection{Extraction of Houses}

Step 1: Co-registration between orthoimagery and LiDAR point cloud data. Figure 7 is the result for co-registration between orthoimagery and LiDARdata point using XY geodetic coordinates of the 6 conjugate points.

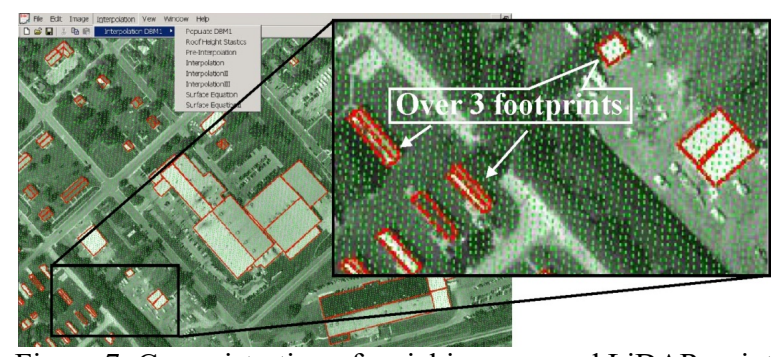

Figure 7: Co-registration of aerial imagery and LiDAR point cloud data (Courtesy of Zhou et al. (2004))

Step 2: Extraction of initial edges of houses from LiDAR point cloud. The coarse boundary of houses can be extracted from LiDAR point cloud using the algorithm described in Section 3.2.2. The result is depicted in Figure 8.

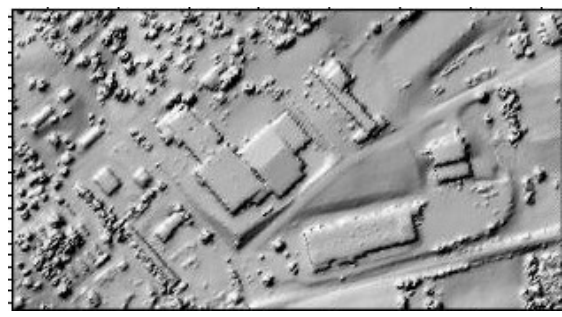

Figure 8: Houses extracted by using single LiDAR data (Courtesy of Ren et al. (2009))

In order to compare the difference, a human-computer interaction is utilized for house extraction. The result is shown in Figure 9. That is Figure 8 is the result of automatic detection of building edge, and Figure 9 is detected buildings after human-computer interactive operation.

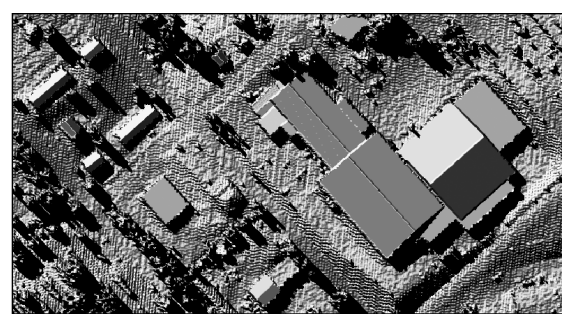

Figure 9. The result of raw LiDAR data interpolation by our software.

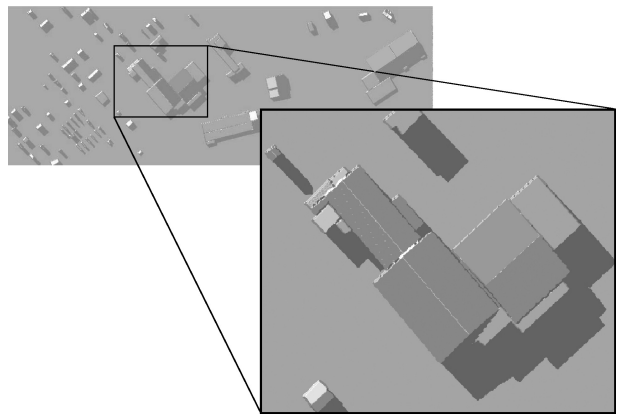

Figure 10: The houses extracted by the proposed method. (Courtesy of Zhou et al. (2004))

Step 3: Creation of accurate 3D model of houses. With the accurate boundary of house, the house 3D model can be created using the method proposed in Section 3.2.3. The major difference between this Step and Step 2 is that boundary information, which is used to fit Eq. (4) for solution of the three unknown parameters. Thus, the boundary of the $3 \mathrm{D}$ model is 
trimmed for creation of an accurate DBM. Repeating the above steps, all houses are modelled (Figure 10).

\section{CONCLUSION}

This paper first overview the advantages and disadvantages of LiDAR and photogrammetry technologies in the creation of DSM, DBM and DTM. It is widely accepted and admitted that a human-computer interactive operation for house extraction is necessary either from LiDAR point cloud data or from highresolution aerial imager. The main contributions of this paper is proposing the combination of the orthorectified aerial imagery (high-resolution orthoimagery) and LiDAR point cloud for DBM generation. In this algorithm, the roof types and surface LiDAR footprints, etc. are described, including the roof surface's boundary and their planar equations.

The experimental field located in Wytheville, Virginia of USA, is used to evaluate the proposed method. The experimental results demonstrated that the proposed method in this paper is capable of effectively extracting houses.

\section{ACKNOWLEDGEMENTS}

Many thanks of my graduate students, including Yexuan $\mathrm{Mu}$, Mingyan Lei, Xiang Zhou, Bo Song for their helps in provision of the figures and experimental results. This paper is financially supported by the National Natural Science of China under Grant numbers 41431179, 41961065; Guangxi Innovative Development Grand Grant under the grant number: GuikeAA18118038, GuikeAA18242048; the National Key Research and Development Program of China under Grant numbers 2016YFB0502501 and the BaGuiScholars program of Guangxi (Guoqing Zhou).

\section{REFERENCES}

Axelsson, P., (1999) Processing of laser scanner dataalgorithms and applications, ISPRS Journal of Photogrammetry \& Remote sensing, vol.54 pp138-147.

Axelsson, P., 2000. DEM Generation from Laser Scanner Data Using Adaptive TIN Models, International Archive of Photogrammetry and Remote Sensing, Vol. XXXIII, Part B4, pp.110-117.

Baillard, C., and H. Maître (1999). 3-D Reconstruction of Urban Scenes from Aerial Stereo Imagery: A Focusing Strategy, Computer Vision and Image Understanding, vol. 76, no. 3, December 1999, pp. 244-258

Baltsavias, E., 1999. A Comparison Between Photogrammetry and Laser Scanning, ISPRS Journal of Photogrammetry \& Remote sensing, vol.54 pp138-147, pp.83-94.

Dong, Hyuk Lee; Kyoung, Mu Lee; Sang, Uk Lee (2008). Fusion of lidar and imagery for reliable building extraction, Photogrammetric Engineering and Remote Sensing, vol. 74, no. 2, pp. 215-225.

Ekhtari, Nima; Valadan Zoej, Mohammad Javad; Sahebi, Mahmod Reza; Mohammadzadeh, Ali (2009). Automatic building extraction from LiDAR digital elevation models and WorldView imagery, Journal of Applied Remote Sensing, vol. 3, no. 1,2009
Fujii, K., Arikawa, T. (2002). Urban object reconstruction using airborne laser elevation image and aerial image. IEEE Trans. on Geoscience and Remote Sensing 40(10), pp.2234-2240.

Gamba, P.; Houshmand, B. (2002). Joint analysis of SAR, LiDAR and aerial imagery for simultaneous extraction of land cover, DTM and 3D shape of buildings, International Journal of Remote Sensing, vol. 23, no. 20, pp. 4439-4450.

Haala, N. 1995. 3D building reconstruction using linear edge segments. In Fitsch, D. Hobbie, D. (Eds), Photogrammetric Week. Wichmann, Karlsruhe, pp. 19-28.

Habib, Ayman; Ghanma, Mwafag; Morgan, Michel; Al-Ruzouq Rami (2005). Photogrammetric and lidar data registration using linear features, Photogrammetric Engineering and Remote Sensing, vol. 71, no. 6, pp. 699-707.

Hermosilla, Txomin; Ruiz, Luis A., Recio, Jorge A.; Estornell, Javier (2011). Evaluation of automatic building detection approaches combining high resolution images and LiDAR data, Remote Sensing, vol. 3, no. 6, pp. 1188-1210.

Hu, Jinhui; You, Suya; Neumann, Ulrich (2007). Integrating LiDAR, aerial image and ground images for complete urban building modeling, third International Symposium on 3D Data Processing, Visualization, and Transmission, 3DPVT 2006, pp. 184-191.

Hug, C. 1997. Extracting artificial objects from airborne laser scanner data. In: Gruen, A. Baltsavias, E., Henricsson, O. (Eds), Automatic Extraction of Man-Made Objects from Aerial and Space Images (II). Birkhaeuser, Basel, pp. 203-212.

Kabolizade, Mostafa; Ebadi, Hamid; Ahmadi, Salman (2010). An improved snake model for automatic extraction of buildings from urban aerial images and LiDAR data. Computers, Environment and Urban Systems, vol. 34, no. 5, pp. 435-441.

Kim, Taejung, Jan-Peter Muller (1996). Automated urban area building extraction from high resolution stereo imagery, Image and Vision Computing, vol. 14, no. 2, pp. 115-130.

Lindenberger, J., 1993. Laser-Profilmessungen zur topographischen Gelaedeaufnahme, Deutsche Geodaetische Kommission, Series C, No. 400, Munich.

Morgan, M. and K. Tempfli (2000). Automatic building extraction from airborne laser scanning data, International Archives of Photogrammetry and Remote Sensing, Amsterdam, 2000, vol. 33, no. B3, pp. 616-623.

Morgan, M., A. Habib, 2002. Interpolation of LiDAR Data and Automatic Building Extraction, ASPRS Annual Conference, CD-ROM, Washington DC, April 19-25.

O'Donohue, Daniel; Mills, Steven; Kingham, Simon; Bartie, Phil; Park, David (2008). Combined thermal-LiDAR imagery for urban mapping, 23rd International Conference Image and Vision Computing New Zealand, IVCNZ, 2008.

$\mathrm{Pu}$, Shi; and Vosselman, George (2009). Knowledge based reconstruction of building models from terrestrial laser scanning data, ISPRS Journal of Photogrammetry and Remote Sensing, vol. 64 , no. 6 , pp. 575-584, November 2009. 
Rottensteiner, Franz; Trinder, John; Clode, Simon; Kubik, Kurt (2007). Building detection by fusion of airborne laser scanner data and multi-spectral images: Performance evaluation and sensitivity analysis, ISPRS Journal of Photogrammetry and Remote Sensing, vol. 62, no. 2, pp. 135-149.

Rottensteiner, Franz (2003). Automatic generation of highquality building models from LiDAR data, IEEE Computer Graphics and Applications, vol. 23, no. 6, pp. 42-50.

Rutzinger, Martin; Rottensteiner, Franz; Pfeifer, Norbert (2009). A comparison of evaluation techniques for building extraction from airborne laser scanning, IEEE Journal of Selected Topics in Applied Earth Observations and Remote Sensing, vol. 2, no. 1, pp. 11-20.

Sampath, Aparajithan; Shan, Jie (2007). Building boundary tracing and regularization from airborne lidar point clouds, Photogrammetric Engineering and Remote Sensing, v 73, n 7, p 805-812.

Schenk, T., and B. Csatho (2002). Fusion of lidar data and aerial imagery for a more complete surface description, International Archives of the Photogrammetry, Remote Sensing and Spatial Information Sciences Science, Vol. XXXIV, pp. 301-317.

Simonetto, Elisabeth; Oriot, Hélène; Garello René (2005). Rectangular building extraction from stereoscopic airborne radar images, IEEE Transactions on Geoscience and Remote Sensing, vol. 43, no. 10, pp. 2386-2395.

Sithole, George and Vosselman, George (2004). Experimental comparison of filter algorithms for bare-Earth extraction from airborne laser scanning point clouds, ISPRS Journal of Photogrammetry and Remote Sensing, vol. 59, no. 1-2, pp. 85101.

Sohn, Gunho; Dowman, Ian (2007). Data fusion of highresolution satellite imagery and LiDAR data for automatic building extraction, ISPRS Journal of Photogrammetry and Remote Sensing, vol. 62, no. 1, pp. 43-63.

Vosselman, G., (2000). Slope Based Filtering of Laser Altimetry Data, International Archives of Photogrammetry and Remote Sensing, Vol. XXXIII PartB3, Amsterdam 2000, pp.935-942.

Wang, Lu and Neumann, Ulrich (2009). A robust approach for automatic registration of aerial images with untextured aerial LiDAR data, IEEE Computer Society Conference on Computer Vision and Pattern Recognition Workshops, CVPR Workshops 2009, pp. 2623-2630

Wehr, A., Lohr,U., 1999. Airborne Laser Scanning - an Introduction and Overview, ISPRS Journal of Photogrammetry and Remote Sensing, Vol., 54, pp.68-82.

Yoon, Jong-suk, J. Shan, 2002. Urban DEM generation from raw airborne LiDAR data, ASPRS Annual Conference, CDROM, Washington DC, April 19-25.

Yu, Ye; Buckles, Bill P.; Liu, Xiaoping (2009). Residential building reconstruction based on the data fusion of sparse LiDAR data and satellite imagery, Lecture Notes in Computer
Science, v 5876 LNCS, n PART 2, p 240-251, 2009, Advances in Visual Computing - 5th International Symposium, ISVC 2009.

Zabuawala, Sakina; Nguyen, Hieu; Wei, Hai; Yadegar, Jacob (2009). Fusion of LiDAR and aerial imagery for accurate building footprint extraction, Proceedings of SPIE - The International Society for Optical Engineering, IS and $\mathrm{T}$ Electronic Imaging - Image Processing: Machine Vision Applications, vol. 7251.

Zhang, K., Yan, J., Chen, S. (2006). Automatic construction of building footprints from airborne LiDAR data. IEEE Trans. on Geoscience and Remote Sensing, vol. 44, no. 9, pp.2523-2532.

Zhou, G. and X. Zhou. Seamless Fusion of LiDAR and Aerial Imagery for Building Extraction, IEEE Trans. on Geoscience and Remote Sensing, vol. 52 , no. 11, 2014, pp. $7393-7407$.

Ren, Z., M. Cen, and G. Zhou, Filtering method of LIDAR data based on contours, Journal of Remote Sensing, vol. 13, no. 1, 2009, pp. 55-62 (Chinese)

Zhou, G., Xiang Zhou, Jiazhi Yang, Yue Tao, Xueqin Nong, Oktay Baysal, Flash Lidar Sensor using Fiber Coupled APDs, IEEE Sensor Journal, vol. 15, no. 9, September, 2015, pp. $4758-4768$

Zhou, G., C. Song, J. Simmers, and P. Cheng (2004). Urban 3D GIS from LiDAR and digital aerial images, Computers and Geosciences, vol. 30, pp. 345-353.

Zhou, G., W. Chen, and J. Kelmelis (2005). A comprehensive study on urban aerial image orthorectification, IEEE Trans. on Geosciene and Remote Sensing, vol. 43, no. 9, pp. 2138-2147, 2005. 